\title{
GSTM1 null and GSTT1 null: predictors of cisplatin-caused acute ototoxicity measured by DPOAEs
}

\author{
Barna Budai ${ }^{1}$ (1) • Péter Prekopp ${ }^{2}$ - László Noszek ${ }^{3}$ - Erika R. Kovács ${ }^{4}$ • Márta Szőnyi ${ }^{5}$ • Dániel J. Erdélyi ${ }^{4}$. \\ Krisztina Bíró ${ }^{6} \cdot$ Lajos Géczi $^{6}$
}

Received: 16 January 2020 / Revised: 5 May 2020 / Accepted: 7 May 2020 / Published online: 20 May 2020

(C) The Author(s) 2020

\begin{abstract}
Preventing the ototoxicity caused by cisplatin is a major issue yet to be overcome. Useful preventive treatments will soon be available. Consequently, the next step is to filter out those patients who are more prone to develop ototoxicity. The aim of this study was to prospectively evaluate potential predictive markers of acute ototoxicity as determined by measures of distortion product otoacoustic emissions (DPOAEs). A total of 118 patients from our previous DPOAE analysis were put under evaluation. Ototoxic cases were divided according to unilateral $(n=45)$ or bilateral $(n=23)$ involvement. The clinicopathological characteristics, hearing test results, germline GSTT1, GSTM1, and GSTP1 polymorphisms, and common laboratory parameters were included in the new analysis. Univariate and multivariate statistical tests were applied. According to multivariate logistic regression, the only independent predictor of unilateral ototoxicity (vs. non-affected) was a GSTM1 null genotype ( $\mathrm{OR}=4.52 ; 95 \% \mathrm{CI}=1.3-16.3$ ), while for bilateral damage, the GSTT1 null genotype $(\mathrm{OR}=4.76 ; 1.4-16)$ was a predictor. The higher starting serum urea level was characteristic of bilateral ototoxicity; however, the only independent marker of bilateral (vs. unilateral) ototoxicity was the presence of GSTT1 null genotype (OR $=2.44 ; 1.23-4.85)$. Different processes, involving the GSTM1 and GSTT1 genotypes, respectively, govern the development of acute unilateral and bilateral ototoxicities. Further research is needed to clarify these processes. Based on the above findings, patients whom are at risk may be selected for otoprotective therapies.
\end{abstract}

\section{Key messages}

- The acute ototoxicity was determined by DPOAE in 118 testicular cancer patients.

- GSTM1 null was the only marker of unilateral ototoxicity (vs. non-affected).

- The only marker of bilateral hearing loss (vs. non-affected) was the GSTT1 null.

- GSTT1 null was also the marker of bilateral vs. unilateral ototoxicity.

- A high-risk group may be selected for new, individualized otoprotective treatment.

Barna Budai and Péter Prekopp contributed equally to this work.

Barna Budai

budai@oncol.hu

1 Department of Molecular Genetics, National Institute of Oncology, Rath Gy. u. 7-9, Budapest 1122, Hungary

2 Department of Otorhinolaryngology, Head and Neck Surgery, Semmelweis University, Budapest, Hungary

3 ENT Department, Szent Imre Hospital, Budapest, Hungary

4 2nd Department of Pediatrics, Semmelweis University, Budapest, Hungary

5 Department of Oncology, "Szent Margit" Hospital, Budapest, Hungary

6 Department of Medical Oncology and Clinical Pharmacology "C", National Institute of Oncology, Budapest, Hungary
Keywords Acute ototoxicity · Cisplatin - DPOAEs · GST polymorphisms $\cdot$ Testicular cancer

\section{Introduction}

Germ cell tumors are among the most frequent neoplasms identified in men from 15-44 years of age [1], even at an advanced stage germ cell tumors can be successfully treated by the use of a combination of chemotherapeutical regimens [2]. In the past decades, the 5-year tumor-free survival rate gradually improved and now it exceeds $90 \%$. One of the most important components of the combined chemotherapeutic regimen is cisplatin with its most frequently appearing side effect, ototoxicity [3]. One of the major requirement from a chemotherapeutic drug is to assure the long-term survival of patients, 
which can be achieved by applying the potentially ototoxic platinum compounds. In clinical practice, ototoxicity is the major dose-limiting side effect of cisplatin treatments [4]. The reported incidence of cisplatin ototoxicity varies from 9 to $91 \%$, based on the differences in chemotherapeutical regimens, patients population, and the definition of ototoxicity, along with variations and inconsistencies in the assessment and grading of hearing loss [5]. Preventing ototoxicity is crucial; however currently available methods to avoid ototoxic side effects are limited, even in the case of endangered patients: use of platinum drugs with less ototoxic potential (usually carboplatin) [4], reduced dose of cisplatin [6], use of otoprotective drugs [7-10], or advices to avoid concomitant or further noise injuries [3], etc. Many ongoing clinical trials are addressing this issue suggests that useful preventive treatments will soon be available [4]. Consequently, the next step is to identify those patients, who are going to develop ototoxicity; however, predicting which patients will experience ototoxicity is a significant clinical challenge. The risk of developing hearing loss from drugs is most often correlated with dosage, but this correlation is highly variable. Individual susceptibility to hearing damage is influenced by multiple biochemical, physiologic, and genetic factors [11]. By using results from international literatures [12-14], it can be concluded that the appearance of ototoxic effect of platinumcontaining chemotherapeutic drug is influenced by the presence or absence of certain types of glutathione-S-transferase (GST) enzymes, which are partly responsible for cisplatin metabolism. These earlier experiments were retrospectively conducted and subjective methods using audiometers were utilized for the audiological measurements.

The aim of this study was to prospectively investigate for possible predictive markers of acute ototoxicity, which was determined by using distortion product otoacoustic emission (DPOAE) measurements. The study evaluated the modifications in the acute phase immediately after the 1st cisplatin cycle; thus, the findings do not address changes in DPOAEs due to chronicity or permanent damage to the cochlea. Besides GSTT1, GSTM1, and GSTP1 polymorphisms, other laboratory parameters and past records of hearing tests were examined. The a priori identification of a high-risk group can served the basis for a better definition of individualized treatment and the targeted use of new otoprotective drugs.

\section{Experimental details}

\section{Patients}

A total of 118 patients with testicular cancer were treated with combination of cisplatin + bleomycin + etoposide were considered for the investigation of predictive markers for acute ototoxicity. These patients represent a subcohort (i.e., those without missing laboratory data) of patients presented in our previous study [15].

The Institutional Ethical Committee and the Hungarian Medical Research Council approved the study (323-101/ 2005-1018EKU). All patients signed an informed consent.

\section{Hearing evaluation and identification of ototoxicity}

At the treatment site, patient's clinical records were reviewed for the following factors: past hearing complaints, present hearing complaints, noise injuries, exposure to noise pollution, hearing loss risk factors, and smoking habits. The historical data were also considered in the analysis. The description of DPOAE measurement and the exclusion criteria for patients including presbyacusis, abnormal tympanic cavity pressure, etc. were detailed in our previous study [15]. Ototoxicity was established by measuring DPOAEs separately for both ears before and immediately after the 1 st cycle of cisplatinbased chemotherapy at $100 \mathrm{mg} / \mathrm{m}^{2} / 5$ days.

The ototoxic effect of cisplatin is known to primarily occur at higher frequencies [16]; therefore, to correctly select the affected patients, only the frequencies 2, 3, 4, 6, and $8 \mathrm{kHz}$ were considered. Dreisbach et al. [17] concluded that "overall, a 4-9 dB change in DPOAE level is considered statistically significant for short, long term monitoring of DPOAEs at frequencies lower than $8 \mathrm{kHz}$." According to Reavis et al. [18], the standard error of DPOAE measurement (SEM) was defined by test-retest changes, and the $90 \%$ DPOAE shift reference intervals were calculated for each frequency. The reference intervals were as follows: $\pm 5.47 \mathrm{~dB}$ at $2 \mathrm{kHz} ; \pm$ $5.81 \mathrm{~dB}$ at $3 \mathrm{kHz} ; \pm 6.14 \mathrm{~dB}$ at $4 \mathrm{kHz} ; \pm 6.92 \mathrm{~dB}$ at $6 \mathrm{kHz}$; and $\pm 5.83 \mathrm{~dB}$ at $8 \mathrm{kHz}$. Based on the above statement and the calculated reference intervals, we defined acute ototoxicity at $\mathrm{a} \geq 7 \mathrm{~dB}$ decrease in DPOAE amplitudes. Moreover, patients were considered unilaterally or bilaterally affected. Out of 118 patients, 23 presented with bilateral and 45 with unilateral ototoxicity (Fig. 1). In both groups, $67 \%$ of patients showed significant changes in at least one of the two highest frequencies. In $46 \%$ of affected patients, a significant DPOAE shift was detected in two or more frequencies in at least one ear.

\section{Clinicopathological parameters}

In addition to patient's age, histology result (seminoma vs. non-seminoma), disease stage ( 1 vs. $2-3$ ), and blood pressure (normotension vs. hypertension) at the beginning of treatment were used in the analysis. The following laboratory data were recorded before the treatment were used for the analysis: white blood cell and platelet count, serum level of hemoglobin and hematocrit, and levels of aspartate aminotransferase, alanine transaminase, gamma-glutamyl transferase, urea, creatinine, glucose, bilirubin, $\mathrm{Na}, \mathrm{K}, \mathrm{Ca}$, and $\mathrm{Mg}$. At the end of the first treatment cycle, the white blood cell and platelet count; serum 
Fig. 1 Results of DPOAE measurement according to the number of affected ears. The values are expressed as mean DPOAE before (solid line) and after (dotted line) the 1st cisplatin cycle. $*$ In 23 patients the right ear and in 22 patients the left ear was affected

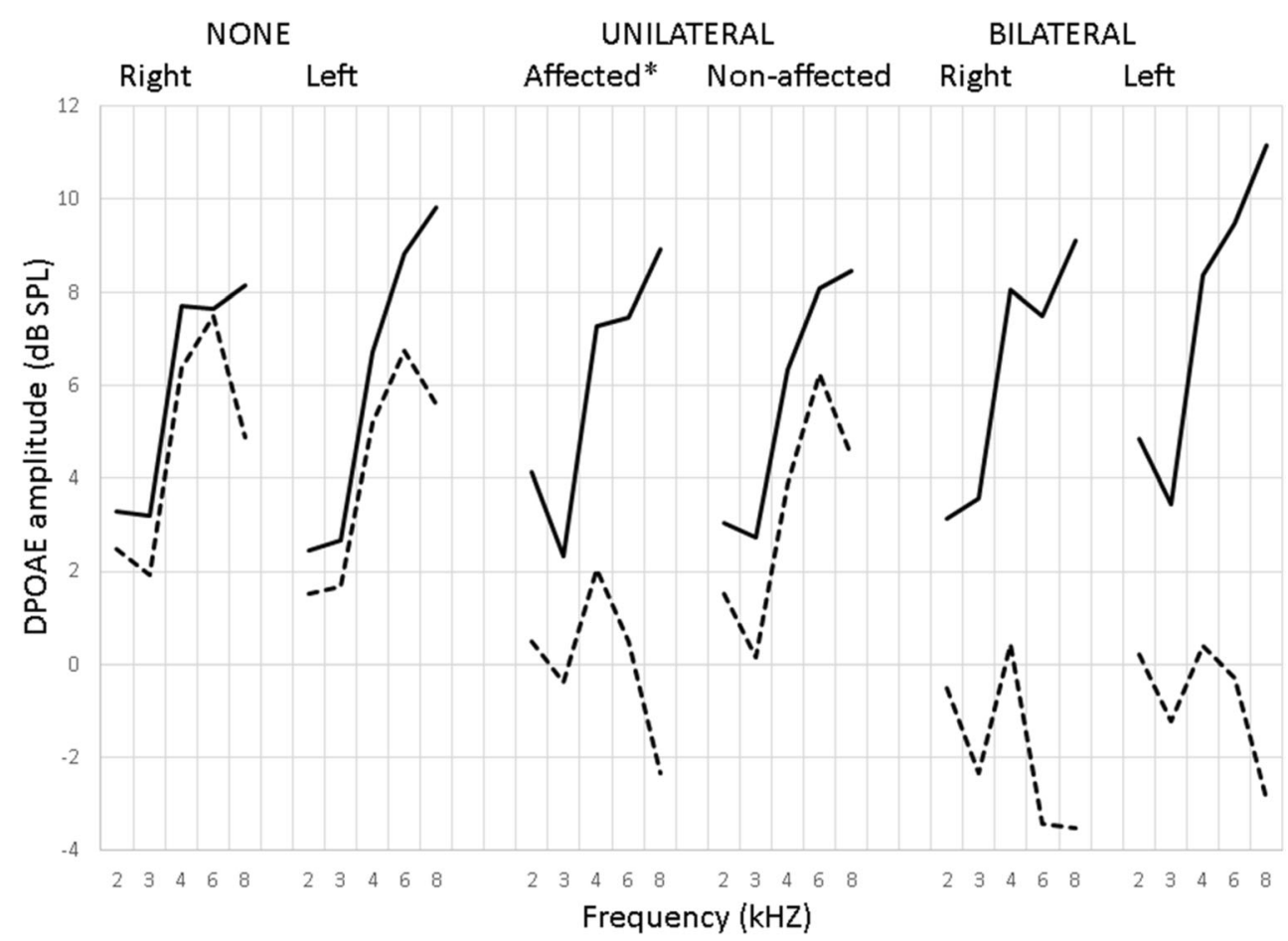

level of hemoglobin, hematocrit, and urea; and creatinine levels were available for investigation.

\section{Genotyping}

Blood samples were taken from patients and DNA prepared as described earlier [19]. GSTT1 and GSTM1 null genotypes and the GSTP1 Ile105Val (rs1695) polymorphism were evaluated by multiplex PCR and the PCR-RFLP method, respectively, as described in detail by Kiran et al [20].

\section{Statistical analyses}

All continuous and categorical data were compared in the three subgroups with one-way ANOVA (or Kruskal-Wallis) and chi-squared (or exact) tests, respectively. Post hoc tests were applied to find all pairwise differences between the subgroups. In the case of parameters available before and after treatment, the changes were also analyzed. $P<0.05$ value was considered statistically significant. A series of logistic regressions were applied to find independent markers of unilateral and bilateral, or any ototoxicity, and, moreover, to differentiate between unilateral and bilateral ototoxicities. All variables, with $P<0.1$ of post hoc tests in univariate analysis, were introduced in the respective logistic regression analysis to determine the independent markers of acute ototoxicity. The Hardy-Weinberg equilibrium was tested for GSTP1 polymorphism on www.dr-petrek.eu/documents/HWE.xls. The NCSS program (NCSS 12 Statistical Software (2018). NCSS, LLC.
Kaysville, Utah, USA, ncss.com/software/ncss.) was used for the statistical analyses.

\section{Results}

The distribution of the clinicopathological parameters of the patients are presented in Table 1.

In the case of the GSTP1, there was no deviation from the Hardy-Weinberg equilibrium $(P=0.195)$. The frequency of the null genotypes of GSTT1 and GSTM1 was $21.2 \%$ and $47.5 \%$, respectively, (see Table 1).

There was a statistically significant accumulation of patients (43\%) with the GSTT1 null genotype presenting with bilateral ototoxicity (Table 1), while the distribution of the null genotype was lower for unaffected or unilaterally affected patients (20\% and $11 \%$, respectively). The presence of the GSTM1 null genotype was significantly more frequent in patients with only one ear involvement $(60 \%)$, while this value was $38-43 \%$ for the other subgroups.

In comparison with the pre-treatment measures, white blood cell count and urea level significantly increased at the end of first cycle, while the hemoglobin, hematocrit, and creatinine levels were decreased (Wilcoxon signed-rank test) in all subgroups, except for the white blood cell count and the urea level in patients with bilateral ototoxicity.

The initial level of urea was higher in patients with acute bilateral ototoxicity than in the other two subgroups $(P=0.02$ and $P=0.023$ ). Interestingly, this high initial level of serum urea remained unchanged even after the 1 st cycle of 
Table 1 Hearing test results and genomic and laboratory parameters of the patients according to ototoxicity (none, unilateral, or bilateral) measured by DPOAEs

\begin{tabular}{|c|c|c|c|}
\hline \multirow[t]{2}{*}{ Parameters } & \multicolumn{3}{|c|}{ Patients presenting ototoxicity } \\
\hline & $\begin{array}{l}\text { None }(N=50) \\
\text { Median }(95 \% \mathrm{CI})\end{array}$ & $\begin{array}{l}\text { Unilateral }(N=45) \\
\text { Median }(95 \% \mathrm{CI})\end{array}$ & $\begin{array}{l}\text { Bilateral }(N=23) \\
\text { Median }(95 \% \mathrm{CI})\end{array}$ \\
\hline $\begin{array}{l}\text { Age (range) } \\
\text { [years] }\end{array}$ & $31.5(29$ to 36$)$ & 34 (32 to 36$)$ & $33(28$ to 40$)$ \\
\hline $\begin{array}{l}\text { Histology } \\
\text { seminoma/non-seminoma }\end{array}$ & $13 / 37$ & $12 / 33$ & $3 / 20$ \\
\hline $\begin{array}{l}\text { Stage } \\
1 / 2-3\end{array}$ & $17 / 33$ & $20 / 25$ & $12 / 11$ \\
\hline Former hearing complaints $\mathrm{n} / \mathrm{y} / \mathrm{NA}$ & $36 / 2 / 12$ & $27 / 5 / 13$ & $11 / 2 / 10$ \\
\hline $\begin{array}{l}\text { Noise injury } \\
\mathrm{n} / \mathrm{y} / \mathrm{NA}\end{array}$ & $24 / 14 / 12$ & $19 / 13 / 13$ & $6 / 7 / 10$ \\
\hline $\begin{array}{l}\text { Noise pollution } \\
\mathrm{n} / \mathrm{y} / \mathrm{NA}\end{array}$ & $23 / 15 / 12$ & $19 / 13 / 13$ & $6 / 7 / 10$ \\
\hline $\begin{array}{l}\text { Hearing loss risk factors } \\
\text { n/y/NA }\end{array}$ & $30 / 9 / 11$ & $20 / 14 / 11$ & $7 / 7 / 9$ \\
\hline $\begin{array}{l}\text { Hearing complaints } \\
\text { before the } 1 \text { st cycle } \mathrm{n} / \mathrm{y} / \mathrm{NA}\end{array}$ & $36 / 0 / 14$ & $30 / 1 / 14$ & $12 / 0 / 11$ \\
\hline $\begin{array}{l}\text { Hearing complaints } \\
\text { after the } 1 \text { st cycle } n / y / N A\end{array}$ & $31 / 6 / 13$ & $26 / 5 / 14$ & $11 / 2 / 10$ \\
\hline $\begin{array}{l}\text { Smoking ever } \\
\mathrm{n} / \mathrm{y} / \mathrm{NA}\end{array}$ & $13 / 25 / 12$ & $13 / 19 / 13$ & $2 / 11 / 10$ \\
\hline $\begin{array}{l}\text { Hypertension } \\
\text { before the } 1 \text { st cycle } \mathrm{n} / \mathrm{y} / \mathrm{NA}\end{array}$ & $31 / 9 / 10$ & $18 / 11 / 16$ & $10 / 5 / 8$ \\
\hline $\begin{array}{l}\text { GSTT1 } \\
\text { wild type/null }\end{array}$ & $40 / 10$ & $40 / 5$ & $13 / 10^{*}$ \\
\hline $\begin{array}{l}\text { GSTM1 } \\
\text { wild type/null }\end{array}$ & $31 / 19$ & $18 / 27 * *$ & $13 / 10$ \\
\hline $\begin{array}{l}\text { GSTP1 } \\
\text { wild type/hetero/homo }\end{array}$ & $21 / 25 / 4$ & $22 / 19 / 4$ & $11 / 12 / 0$ \\
\hline $\begin{array}{l}\text { White blood cell count } \\
\text { before the } 1 \text { st cycle }[\mathrm{G} / \mathrm{L}]\end{array}$ & $7.5(6.5$ to 8.4$)$ & $7.5(6.8$ to 8.5$)$ & $7.3(6.5$ to 9.1$)$ \\
\hline $\begin{array}{l}\text { White blood cell count } \\
\text { after the } 1 \text { st cycle }[\mathrm{G} / \mathrm{L}]\end{array}$ & $8.5(7.7$ to 9.5$)$ & 8.7 (8.1 to 9.6$)$ & 8.1 (7.1 to 8.7$)$ \\
\hline $\begin{array}{l}\text { White blood cell count } \\
\text { change [\% of before] }\end{array}$ & $6(-5$ to 12.7$)$ & 13.3 (2.5 to 26.7$)$ & $8.1(-3.9$ to 23.2$)$ \\
\hline $\begin{array}{l}\text { Hemoglobin } \\
\text { before the } 1 \text { st cycle }[\mathrm{mmol} / \mathrm{L}]\end{array}$ & $14.8(14.4$ to 15.1$)$ & 15.1 (14.6 to 15.4$)$ & $14.7(13.9$ to 15.5$)$ \\
\hline $\begin{array}{l}\text { Hemoglobin } \\
\text { after the } 1 \text { st cycle }[\mathrm{mmol} / \mathrm{L}]\end{array}$ & 13.7 (13.1 to 14$)$ & $13.9(13.5$ to 14.2$)$ & $13.6(12.8$ to 14.3$)$ \\
\hline $\begin{array}{l}\text { Hemoglobin } \\
\text { change [ } \% \text { of before] }\end{array}$ & $-6.7(-8.9$ to -4.9$)$ & $-7.7(-9.4$ to -4.9$)$ & $-6.5(-10.6$ to -3.5$)$ \\
\hline $\begin{array}{l}\text { Hematocrit } \\
\text { before the } 1 \text { st cycle }[\mathrm{L} / \mathrm{L}]\end{array}$ & $0.44(0.44$ to 0.46$)$ & $0.45(0.44$ to 0.47$)$ & $0.45(0.43$ to 0.47$)$ \\
\hline $\begin{array}{l}\text { Hematocrit } \\
\text { after the } 1 \text { st cycle }[\mathrm{L} / \mathrm{L}]\end{array}$ & 0.41 (0.4 to 0.42$)$ & 0.41 (0.4 to 0.42$)$ & $0.41(0.38$ to 0.42$)$ \\
\hline $\begin{array}{l}\text { Hematocrit } \\
\text { change [\% of before] }\end{array}$ & $-7.3(-10.9$ to -5.4$)$ & $-8.6(-10.6$ to -6.5$)$ & $-8.8(-12.8$ to -4.9$)$ \\
\hline $\begin{array}{l}\text { Platelet count } \\
\text { before the } 1 \text { st cycle }[\mathrm{G} / \mathrm{L}]\end{array}$ & 254 (240 to 275$)$ & 249 (229 to 266$)$ & 247 (225 to 297$)$ \\
\hline $\begin{array}{l}\text { Platelet count } \\
\text { after the } 1 \text { st cycle }[\mathrm{G} / \mathrm{L}]\end{array}$ & 268 (234 to 296$)$ & 251 (219 to 270$)$ & 221 (208 to 282$)$ \\
\hline $\begin{array}{l}\text { Platelet count } \\
\text { change [\% of before] }\end{array}$ & $-3.1(-38$ to 4.9$)$ & $0(-2.6$ to 4.7$)$ & $-2.7(-9$ to 2.5$)$ \\
\hline $\begin{array}{l}\text { Creatinine } \\
\text { before the } 1 \text { st cycle }[\mu \mathrm{mol} / \mathrm{L}]\end{array}$ & 89 (84 to 94$)$ & 89 (81 to 95$)$ & 89 (85 to 94$)$ \\
\hline $\begin{array}{l}\text { Creatinine } \\
\text { after the1st cycle }[\mu \mathrm{mol} / \mathrm{L}]\end{array}$ & 89 (78 to 92$)$ & $82(77$ to 89$)$ & 87 (79 to 98$)$ \\
\hline Creatinine & $-1.8(-10.1$ to 2.5$)$ & $-3.2(-12.9$ to 0$)$ & $-5.7(-11.7$ to 1.4$)$ \\
\hline
\end{tabular}


Table 1 (continued)

\begin{tabular}{|c|c|c|c|}
\hline \multirow[t]{2}{*}{ Parameters } & \multicolumn{3}{|c|}{ Patients presenting ototoxicity } \\
\hline & $\begin{array}{l}\text { None }(N=50) \\
\text { Median }(95 \% \mathrm{CI})\end{array}$ & $\begin{array}{l}\text { Unilateral }(N=45) \\
\text { Median }(95 \% \mathrm{CI})\end{array}$ & $\begin{array}{l}\text { Bilateral }(N=23) \\
\text { Median }(95 \% \mathrm{CI})\end{array}$ \\
\hline $\begin{array}{l}\text { Urea } \\
\text { before the } 1 \text { st cycle }[\mathrm{mmol} / \mathrm{L}]\end{array}$ & $4.2(3.9$ to 4.9$)$ & $4.6(4.2$ to 5$)$ & $5.2(4.8 \text { to } 5.9)^{* * *}$ \\
\hline $\begin{array}{l}\text { Urea } \\
\text { after the } 1 \text { st cycle }[\mathrm{mmol} / \mathrm{L}]\end{array}$ & 5 (4.6 to 5.3$)$ & $5.6(4.9$ to 6.2$)$ & $4.9(4.6$ to 6.3$)$ \\
\hline $\begin{array}{l}\text { Urea } \\
\text { change [ } \% \text { of before] }\end{array}$ & $12.2(0$ to 28.6$)$ & $15.5(7.1$ to 35.4$)$ & $-1.7(-12.9 \text { to } 15)^{* * * *}$ \\
\hline $\begin{array}{l}\text { Aspartate aminotransferase } \\
\text { [IU/L] }\end{array}$ & 23 (21 to 27$)$ & 24 (23 to 26$)$ & $23(21$ to 26$)$ \\
\hline $\begin{array}{l}\text { Alanine transaminase } \\
{[\mathrm{IU} / \mathrm{L}]}\end{array}$ & 26.5 (20 to 30$)$ & 28 (25 to 33$)$ & $25(20$ to 31$)$ \\
\hline $\begin{array}{l}\text { Gamma-glutamyl transferase } \\
\text { [IU/L] }\end{array}$ & $33.5(25$ to 40$)$ & 41 (34 to 47$)$ & $33(27$ to 40$)$ \\
\hline $\begin{array}{l}\text { Glucose } \\
{[\mathrm{mmol} / \mathrm{L}]}\end{array}$ & $5.2(4.9$ to 5.4$)$ & $5.1(5$ to 5.3$)$ & $5.2(5.1$ to 5.8$)$ \\
\hline $\begin{array}{l}\text { Bilirubin } \\
{[\mu \mathrm{mol} / \mathrm{L}]}\end{array}$ & $11.2(8.5$ to 13.5$)$ & $11.3(9.4$ to 14$)$ & $10.6(8$ to 16.2$)$ \\
\hline $\begin{array}{l}\mathrm{Na} \\
{[\mathrm{mmol} / \mathrm{L}]}\end{array}$ & 138 (137 to 138$)$ & 138 (137 to 139$)$ & 139 (138 to 140$)$ \\
\hline $\begin{array}{l}\mathrm{K} \\
{[\mathrm{mmol} / \mathrm{L}]}\end{array}$ & 4.5 (4.3 to 4.6$)$ & $4.4(4.3$ to 4.6$)$ & $4.3(4.2$ to 4.5$)$ \\
\hline $\begin{array}{l}\mathrm{Ca} \\
{[\mathrm{mmol} / \mathrm{L}]}\end{array}$ & 2.5 (2.45 to 2.54$)$ & 2.5 (2.46 to 2.52$)$ & 2.5 (2.49 to 2.55$)$ \\
\hline $\begin{array}{l}\mathrm{Mg} \\
{[\mathrm{mmol} / \mathrm{L}]}\end{array}$ & $0.85(0.83$ to 0.89$)$ & $0.84(0.82$ to 0.87$)$ & 0.85 (0.8 to 0.87$)$ \\
\hline
\end{tabular}

$C I$ confidence interval, hetero heterozygous, homo homozygous mutant, $n$ no, $N A$ not available, $y$ yes

${ }^{*} P=0.008$ ( 0 vs. $2 P=0.037 ; 1$ vs. $\left.2 P=0.002\right)$

*** 0 vs. $1 P=0.032$

**** $P=0.034$ ( 0 vs. $2 P=0.02 ; 1$ vs. $2 P=0.023)$

***** $P=0.031(1$ vs. $2 P=0.007)$

chemotherapy, while in the other subgroups, $a \sim 20 \%$ increase was observed.

The following variables were introduced in the logistic regression model of 0 vs. 1 involved ear: GSTM1, "urea after," and aspartate aminotransferase. Only the presence of the GSTM1 null proved to be an independent marker of unilateral ototoxicity with $\mathrm{OR}=3.62 ;(95 \%$ CI $1.3-10.5) ; P=0.018$. The area under the receiver operating curve (ROC) was 0.624 .

The GSTT1, glucose, and urea levels were used as covariates in the logistic regression model for $0 \mathrm{vs}$. two affected ears. Only the GSTT1 null was an independent marker of bilateral ototoxicity: $\mathrm{OR}=3.6 ;(1.1-11.4) ; P=0.029$. The area under the ROC curve was 0.617 .

The model for unilateral vs. bilateral involvement included the following parameters: the GSTT1, urea, glucose, and "white blood cell count after," while "urea change" was excluded because of a multicollinearity. Only the GSTT1 null was found to be an independent predictor of acute bilateral ototoxicity compared with unilateral damage: $\mathrm{OR}=4.31$; (2.8-4.3); $P=0.033$. The area under the ROC curve was 0.706 .
If ototoxicity (either or both ears involved vs. non-affected patients) was considered and age and GSTM1 were used as covariates, logistic regression resulted in no significant variables.

\section{Discussion}

In this study, we aimed to evaluate the potential predictive markers of cisplatin-caused acute ototoxicity as determined by DPOAEs to give further assistance to oncologists in designing individual therapies for patients at risk. DPOAE measures indicated earlier damage of outer hair cells compared with the outcomes of routine audiometric tests [21]. In our previous study [15], acute ototoxicity was demonstrated by measuring DPOAEs before and after the 1st cycle of a cisplatin-based treatment in patients with testicular cancer. In the present report, we divided patients into three subgroups according to the nature of ototoxicity, i.e., no ototoxicity, unilateral toxicity, and bilateral ototoxicity. Data regarding hearing complaints, routine laboratory parameters, and three germline genetic polymorphisms (GSTM1, GSTT1, and 
GSTP1) were investigated. The frequencies of GSTM1 null and GSTT1 null genotypes were similar to those published for a Hungarian population ( $47.4 \%$ and $20.6 \%$, respectively) [22]. The distributions of GSTP1 genotypes were in HardyWeinberg equilibrium. We have observed that a GSTM1 null was associated with unilateral involvement, while the GSTT1 null was associated with a bilateral acute ototoxicity. It is likely that other non-investigated parameters can also contribute to the development of an ototoxicity, because the observed areas under the ROC curves for both markers were $\sim 0.6$.

There are few reports, which have studied GST polymorphisms in cisplatin-induced acute toxicity (see Table 2). To our knowledge, this is the first study investigating the role of GSTM1, GSTT1, and GSTP1 polymorphisms in acute ototoxicity after the 1 st cycle of cisplatin determined by DPOAEs in patients with testicular cancer. Khrunin et al. did not find any association between the GSTM1, GSTT1, or GSTP1 gene variants, and ototoxicity measured audiometrically after the 2 nd cycle of cisplatin [23]. Talach et al. and Jurajda et al. measured ototoxicity by pure-tone audiometry and found significant associations with the GSTT1 +/+ genotype both after the 1st and 2nd cisplatin cycles $[12,24]$. Barahmani et al. also investigated GST polymorphisms in patients presenting with a grade 3 audiologic toxicity during cisplatin treatment, but there was

Table 2 Association between ototoxicity and studied GST polymorphisms

\begin{tabular}{|c|c|c|c|c|c|c|c|}
\hline Study & $n$ & Ototoxicity & $\begin{array}{l}\text { Cumulative } \\
\text { dose } \\
\mathrm{m} \mathrm{g} \mathrm{/} \mathrm{m}^{2} \\
\text { cisplatin }\end{array}$ & Method & $\begin{array}{l}\text { GSTT1 } \\
\text { null/null vs others }\end{array}$ & $\begin{array}{l}\text { GSTM1 } \\
\text { null/null vs others }\end{array}$ & $\begin{array}{l}\text { GSTPl } \\
\mathrm{w} / \mathrm{h} / \mathrm{m}\end{array}$ \\
\hline Present & 118 & Early & 100 & DPOAE & $\begin{array}{l}\mathrm{OR}=4.1 ; p=0.004^{\mathrm{a}+\mathrm{b}} \\
(\mathrm{OR}=3.6 ; p= \\
0.029)^{\mathrm{a} * *}\end{array}$ & $\begin{array}{l}\mathrm{OR}=2.4 ; p=0.032^{\mathrm{b}} \\
(\mathrm{OR}=3.6 ; p= \\
0.018)^{\mathrm{b} * *}\end{array}$ & NS \\
\hline [23] & 104 & Early & 200 & PTA & NS & NS & NS \\
\hline $\begin{array}{l}{[12,} \\
24]\end{array}$ & 54 & Early & 100 & PTA & $(\mathrm{OR}=6.4 ; p=0.009)^{*}$ & NS & NS \\
\hline [12, & 38 & Early & 200 & PTA & $(\mathrm{OR}=6.3 ; p=0.027)^{*}$ & NS & NS \\
\hline$[25]$ & 34 & $\begin{array}{l}\text { Any during } \\
\text { CHT }\end{array}$ & $75-600$ & PTA & NS & NS & - \\
\hline [26] & 72 & Late & Median $\sim 400$ & $\begin{array}{l}\text { DPOAE+ } \\
\text { PTA/ABR }\end{array}$ & - & - & $\begin{array}{l}(\mathrm{m} \text { vs others } \mathrm{OR}>1 ; p=0.03) \\
(\mathrm{m} \text { vs others } \mathrm{NS}) * *\end{array}$ \\
\hline [14] & 173 & Late & Median $\sim 400$ & PTA & NS & $\begin{array}{l}\mathrm{NS} \\
(\mathrm{OR}=0.4 ; p= \\
\quad 0.022)^{* *}\end{array}$ & $\begin{array}{l}p=0.021 \\
(\mathrm{~m} \text { vs others } \mathrm{OR}=0.2 ; p< \\
\quad 0.001)^{* *}\end{array}$ \\
\hline [27] & 162 & Late & Median 400 & PTA & - & NS & NS \\
\hline [28] & 106 & Late & Median 400 & PTA & $\begin{array}{l}\mathrm{NS} \\
(\mathrm{OR}=3.5 ; p= \\
\quad 0.038)^{* *}\end{array}$ & NS & $\begin{array}{l}p=0.046 \\
(\mathrm{w} \text { vs others } \mathrm{OR}=3.8 ; p= \\
0.012)^{* *}\end{array}$ \\
\hline [23] & 104 & Late & 600 & PTA & NS & NS & NS \\
\hline [29] & 90 & Late & Median 265 & PTA & $\mathrm{OR}=0.2 ; p=0.01$ & NS & NS \\
\hline [13] & 68 & Late & Median 526 & PTA & $\begin{array}{l}\mathrm{OR}=0.2 ; p=0.023 \\
(\mathrm{OR}=0.1 ; p= \\
0.002)^{* *}\end{array}$ & NS & - \\
\hline [30] & 42 & Late & Mean 635 & PTA & - & - & $\begin{array}{l}\text { (w vs others NS, } \\
\text { but at } \leq 4 \mathrm{kHz} \text { OR }=0.1 ; p=0.02 \text { ) }\end{array}$ \\
\hline [31] & 39 & Late & Mean 236 & PTA & NS & NS & NS \\
\hline [12] & 37 & Late & 600 & PTA & NS (NS)* & - & - \\
\hline [32] & 238 & Late & Median 397 & Self-reported & NS & $\mathrm{OR}=0.6 ; p=0.025$ & $\begin{array}{l}(\mathrm{m} \text { vs others } \mathrm{OR}=0.3 ; p= \\
0.008)^{* *}\end{array}$ \\
\hline [33] & 69 & Late & Median 300 & Hearing aid & - & - & $\begin{array}{l}\text { NS } \\
(\mathrm{w} \text { vs others } \mathrm{OR}=0.3 ; p=0.021)\end{array}$ \\
\hline
\end{tabular}

$A B R$ auditory brainstem response, $C H T$ chemotherapy, DPOAE distorsion product otoacoustic emission, $h$ heterozygous genotype, $m$ homozygous mutant genotype, $N S$ non-significant, PTA pure-tone audiometry, OR odds ratio, $w$ homozygous wild genotype

$*+$ ++ vs others

**Multivariant analysis

${ }^{\mathrm{a}}$ Bilateral

${ }^{\mathrm{b}}$ Unilateral 
no correlation between development or time to the development of ototoxicity and the GST polymorphisms [25]. After presenting these results, we can discuss those studies, which investigated the association between GST gene variants and late ototoxicity. Unfortunately, there are no investigations, which examined the association of these polymorphisms and the late-onset ototoxicity measured by DPOAEs. Olgun et al. [26] reported the use of DPOAEs; but in addition to pure-tone audiometry, unfortunately, the detailed results of DPOAEs were not reported and ototoxicity was considered based only on the audiogram. Peters et al. considered all cycles of cisplatin to define ototoxicity in 39 patients. However, even though the pure-tone audiometry was performed after each cycle, the rate of ototoxic cases was not reported separately after each treatment cycle [31]. Aside from a consistently bilateral involvement, no association was reported for GSTM1, GSTT1, and GSTP1 polymorphisms. Similarly, Ross et al. [27] and Khrunin et al. [23] did not find any significant association between the above gene variants and late-onset ototoxicity. Among others, the significantly higher rate $(69 \%$ vs $46 \%$ in non-affected patients) of concomitant treatments with ototoxic side effects (aminoglycosides and cranial irradiation) of patients with hearing loss [27], or patients' characteristics (women, median 52 years, ovarian cancer), and that cisplatin treatment was stopped if a grade $>1$ of ototoxicity occurred [23] may mask the effect of GST polymorphisms. Talach et al. measured ototoxicity by pure-tone audiometry at the end of cisplatin treatment and found no association with any of the above polymorphisms [12]. Interestingly, before and immediately after the 2 nd cycle and before the 3 rd cycle, they observed a significantly higher rate of ototoxic cases in patients with a wild type GSTT1 (+/+) genotype. If patients with at least one wild type allele were considered (as in our study), the association was not present. Unfortunately, unilateral and bilateral ototoxicites were not assessed.

Based on our previous $[34,35]$ and present experiences and on reports from the literature [36-38], we presume that molecular processes that lead to acute or permanent (late) ototoxicity caused by cisplatin can differ. Therefore, comparison of results from studies on acute and chronic ototoxicity should be avoided as this may account for contradictory results in the literature. For example, Oldenburg et al. investigated hearing impairment after $>4$ years from the start of cisplatin treatment; thus, their findings [32] are not comparable with our results on acute ototoxicity. The contradiction between the results (GSTM1 or GSTT1 null genotype as a protector or facilitator for ototoxicity) relies on different physiological phenomena: early acute ototoxicity may be associated to damage of stria vascularis and supporting cells within the cochlea that have the potential to recover, whereas the damage to outer hair cells results in a permanent hearing loss [37]. In some studies, ototoxicity was only assessed at the completion of chemotherapeutic treatment. Ototoxicity at that stage cannot be compared with acute ototoxicity, because the cumulated cisplatin doses (4-6 $\times$ higher than those for acute events) are similar to those presented for chronic events. The fact of incomparability was mirrored by the findings of Choeyprasert et al. who measured ototoxicity by audiometry, just at the end of therapy, and the GSTT1 null proved to be protective for hearing impairment [13].

The difference between acute and late ototoxicity was also presented in studies by Talach et al. [12] and Jurajda et al. [24] where the early observed significant association of the GSTT1 genotype with ototoxicity disappeared at the end of treatment. According to the data of Table 2, the association between late ototoxicity and the GSTP1 polymorphism is very controversial. Both the homozygous mutant $[14,26,32]$ and the wild genotype $[28,30,33]$ were associated with ototoxicity [26, $28]$ or a protective effect $[14,30,32,33]$, or no effect was found $[23,27,29,31]$.

Interestingly, the GSTT1 null was found to be associated with hearing damage (presbycusis) at high frequencies, which was determined by audiometry in 50 adults [39], while the presence of the GSTM1 null genotype was associated with noise-induced hearing loss as determined by pure-tone audiometry in 889 Chinese workers [40]. The latter result led us to hypothesize that our patients with the GSTM1 null genotype were also prone to noise-induced hearing loss, but a lower noise exposure threshold may be present, because of cisplatin treatment. This presumption should be investigated in further studies.

Regarding the high initial urea levels, acute dehydration can be excluded because the hemoglobin, hematocrit, serum sodium $\left(\mathrm{Na}^{+}\right)$, and potassium $\left(\mathrm{K}^{+}\right)$levels of patients with further bilateral involvement were within the reference ranges (i.e., they were in the middle of the respective normal intervals). Impaired kidney function can also be excluded because the creatinine and the estimated glomerular filtration rate levels (calculated to check the normal kidney function; data not shown) did not differ from those of other patients. Also, drugs (steroids, cytokines, tetracyclines, etc.), which may increase the urea levels of patients, were not initiated before chemotherapy.

Other factors, such as a high protein diet, presence of hidden infection, inflammation or stress, or other cause(s), may raise the urea levels [41]. In order to verify if a systemic inflammation was present or not, we calculated the systemic immune-inflammation index (SII) (as the C-reactive protein was not available for our patients). There was no significant difference between patients with high vs. low urea level (data not shown), which suggested that high urea levels were not caused by systemic inflammation, or the SII was not a good marker for indicating cancer-caused inflammation in this patient group. Moreover, the yet unidentified urea-increasing processes overcome the well-known ureaincreasing effect of cisplatin, which as a later process was observed in our patients. Further investigations should be conducted to reveal the nature of competing processes. On the other hand, a severe (bilateral) ototoxicity may be attributed to the additively enhanced reactive oxygen species formation due to 
existing high urea levels [42] and cisplatin treatment [3]. None of the studied polymorphisms have been associated with urea level; however, our data shows that elevated level of urea at the initiation of therapy in patients, who later developed severe ototoxicity needs further prospective studies.

There are some limitations of this study. We have not investigated the combination of polymorphisms, as did other authors $[14,25]$, because the number of cases in the study groups would not allow enough statistical power for drawing such conclusions. There are several common laboratory parameters and markers related to ototoxicity (e.g., [27, 43]), which were not evaluated in our study, since these parameters were not available for all patients. On the other hand, the statistical power was strong in our analysis.

The role of the studied (and not evaluated in our current work) polymorphisms in predicting cisplatin-caused early ototoxicity is far from being clarified. In the future, the most important task would be to find a key to differentiate between those early ototoxic cases, which will recover, and those who are going to develop a permanent hearing impairment. It needs to be emphasized that early ototoxicity is prone to recovery in some patients [37]. In contrast, other patients presenting with early ototoxicity will develop chronic hearing loss in spite of a dose reduction or changing to other platinum-containing drug. Based on our present results, we may hypothesize that there may be several and different competing molecular mechanisms involving GST and supposedly other reactive oxygen species scavenger enzymes [3], for the development of unilateral and bilateral ototoxicities.

For the association of genotypes with unilateral and bilateral ototoxicity, we have only hypothetical explanations. The asymmetry and the genetic difference of the bilateral organs are also well-known; thus, an association of a genotype with unilateral ototoxicity is possible. Another option may be related to the unilateral noise-induced effect during treatment, which may result in hearing damage, because the ears during treatment are more sensitive to intense noise. However, this sensitivity may be related to some gene variants. Last, but not least, it is hypothesized that two molecular mechanisms with different speeds may cause ototoxicity. Due to the asymmetry of organs (which includes the asymmetry in the expression of enzymes), the slow toxicity becomes first unilateral and then bilateral. Our patients were also tested more than 1 year after treatment. According to our as yet unpublished preliminary results, in cases where the acute unilateral ototoxicity became bilateral, $50 \%$ of patients had GSTM1 null and 0\% had GSTT1 null genotypes. So this could be a GSTM1-dependent slow process. The rapid response is characteristic of GSTT1 null patients, who presented acute and also late (persistent) bilateral ototoxicity: with $67 \%$ of them being GSTT1 null. The situation is further complicated or explained by the fact that improvement is only seen in $12 \%$ of patients and only in unilateral cases, who exhibited $0 \%$ GSTT1 nulls and 67\% GSTM1 nulls. Thus, the slow process involves also reversible ototoxicity, and perhaps this is why it seems slow in the development of bilateral damage. Further research is needed to clarify these phenomena.

In conclusion, GSTM1 null and GSTT1 null genotypes proved to be independent markers of unilateral and bilateral acute ototoxicities, respectively. The a priori identification of a high-risk group can serve as a basis for a better definition of individualized treatment and the targeted use of new otoprotective drugs.

Acknowledgements Open access funding provided by National Institute of Oncology (OOI). We are grateful for critical comments on the manuscript from Nándor Polk M.D., János Papp Ph.D., and Prof. Attila Patócs M.D., D.Sc.

Authors' contributions Study concepts: BB, PP, LN, DJE, KB, LG. Study design: BB, PP, LN, DJE, KB, LG. Data acquisition: PP, LN, ERK, MS. Quality control of data and algorithms: BB, PP, DJE, KB, LG.

Data analysis and interpretation: BB, PP, ERK, MS. Statistical analysis: BB, PP. Manuscript preparation: BB, PP. Manuscript editing: BB. Manuscript review: LN, DJE, KB, LG. All authors have approved the manuscript.

Funding information The authors received financial support from the 2019 Thematic Excellence Program (TUDFO/51757/2019-ITM).

\section{Compliance with ethical standards}

The Institutional Ethical Committee and the Hungarian Medical Research Council approved the study (323-101/2005-1018EKU). All patients signed an informed consent.

Conflict of interest The authors declare that they have no conflict of interest.

Open Access This article is licensed under a Creative Commons Attribution 4.0 International License, which permits use, sharing, adaptation, distribution and reproduction in any medium or format, as long as you give appropriate credit to the original author(s) and the source, provide a link to the Creative Commons licence, and indicate if changes were made. The images or other third party material in this article are included in the article's Creative Commons licence, unless indicated otherwise in a credit line to the material. If material is not included in the article's Creative Commons licence and your intended use is not permitted by statutory regulation or exceeds the permitted use, you will need to obtain permission directly from the copyright holder. To view a copy of this licence, visit http://creativecommons.org/licenses/by/4.0/.

\section{References}

1. Ghazarian AA, Trabert B, Devesa SS, McGlynn KA (2015) Recent trends in the incidence of testicular germ cell tumors in the United States. Andrology 3:13-18

2. Hanna NH, Einhorn LH (2014) Testicular cancer - discoveries and updates. N Engl J Med 371:2005-2016

3. Paken J, Govender CD, Pillay M, Sewram V (2016) Cisplatinassociated ototoxicity: a review for the health professional. $\mathrm{J}$ Toxicol 2016:1809394

4. Callejo A, Sedó-Cabezón L, Juan ID, Llorens J (2015) Cisplatininduced ototoxicity: effects, mechanisms and protection strategies. Toxics 3:268-293 
5. Chang KW (2013) Ototoxicity. In: Johnson TJ, Rosen AC (eds) Bailey's Head \& Neck Surgery, $5^{\text {th }}$ edn. Wolters Kluwer Health pp 2542-2555

6. Caballero M, Mackers P, Reig O et al (2017) The role of audiometry prior to high-dose cisplatin in patients with head and neck cancer. Oncology 93:75-82

7. Gurney JG, Bass JK, Onar-Thomas A et al (2014) Evaluation of amifostine for protection against cisplatin-induced serious hearing loss in children treated for average-risk or high-risk medulloblastoma. Neuro-Oncology 16:848-855

8. Riga MG, Chelis L, Kakolyris S et al (2013) Transtympanic injections of $\mathrm{N}$-acetylcysteine for the prevention of cisplatin-induced ototoxicity: a feasible method with promising efficacy. Am J Clin Oncol 36:1-6

9. Scasso F, Sprio AE, Canobbio L et al (2017) Dietary supplementation of coenzyme Q10 plus multivitamins to hamper the ROS mediated cisplatin ototoxicity in humans: a pilot study. Heliyon 3:e00251

10. Lin CY, Wu JL, Shih TS et al (2010) N-Acetyl-cysteine against noise-induced temporary threshold shift in male workers. Hear Res 269:42-47

11. Reavis KM, Phillips DS, Fausti SA et al (2008) Factors affecting sensitivity of distortion product otoacoustic emissions to ototoxic hearing loss. Ear Hear 29:875-893

12. Talach T, Rottenberg J, Gal B et al (2016) Genetic risk factors of cisplatin induced ototoxicity in adult patients. Neoplasma 63:263-268

13. Choeyprasert W, Sawangpanich R, Lertsukprasert K et al (2013) Cisplatin-induced ototoxicity in pediatric solid tumors: the role of glutathione S-transferases and megalin genetic polymorphisms. J Pediatr Hematol Oncol 35:e138-e143

14. Oldenburg J, Kraggerud SM, Cvancarova M, Lothe RA, Fossa SD (2007) Cisplatin-induced long-term hearing impairment is associated with specific glutathione s-transferase genotypes in testicular cancer survivors. J Clin Oncol 25:708-714

15. Noszek L, Budai B, Prekopp P et al (2017) Early ototoxic changes in patients with germ cell tumor after first cycle of cisplatin-based therapy. Laryngoscope 127:E277-E282

16. Fausti SA, Helt WJ, Phillips DS et al (2003) Early detection of ototoxicity using $1 / 6^{\text {th }}$ octave steps. J Am Acad Audiol 14:444-450

17. Dreisbach L, Zettner E, Chang Liu M et al (2018) High-frequency distortion-product otoacoustic emission repeatability in a patient population. Ear Hear 39:85-100

18. Reavis KM, McMillan GP, Dille MF, Konrad-Martin D (2015) Meta-analysis of distortion product otoacoustic emission retest variability for serial monitoring of cochlear function in adults. Ear Hear 36:e251-e260

19. Budai B, Komlósi V, Adleff V et al (2012) Impact of SHMT1 polymorphism on the clinical outcome of patients with metastatic colorectal cancer treated with first-line FOLFIRI+bevacizumab. Pharmacogenet Genomics 22:69-72

20. Kiran B, Karkucak M, Ozan H et al (2010) GST (GSTM1, GSTT1, and GSTP1) polymorphisms in the genetic susceptibility of Turkish patients to cervical cancer. J Gynecol Oncol 21:169-173

21. Mukherjea D, Rybak LP (2011) Pharmacogenomics of cisplatininduced ototoxicity. Pharmacogenomics 12:1039-1050

22. Csejtei A, Tibold A, Varga Z et al (2008) GSTM, GSTT and p53 polymorphisms as modifiers of clinical outcome in colorectal cancer. Anticancer Res 28:1917-1922

23. Khrunin AV, Moisseev A, Gorbunova V, Limborska S (2010) Genetic polymorphisms and the efficacy and toxicity of cisplatinbased chemotherapy in ovarian cancer patients. Pharm J 10:54-61

24. Jurajda M, Talach T, Kostřica R, Lakomý R, Kocák I, Cvanová M (2012) Genetic background of cisplatin induced ototoxicity. Klin Onkol 25:184-187

25. Barahmani N, Carpentieri S, Li XN et al (2009) Glutathione Stransferase M1 and T1 polymorphisms may predict adverse effects after therapy in children with medulloblastoma. Neuro-Oncology 11:292-300
26. Olgun Y, Aktaș S, Altun Z et al (2016) Analysis of genetic and non genetic risk factors for cisplatin ototoxicity in pediatric patients. Int J Pediatr Otorhinolaryngol 90:64-69

27. Ross CJ, Katzov-Eckert H, Dubé MP et al (2009) Genetic variants in TPMT and COMT are associated with hearing loss in children receiving cisplatin chemotherapy. Nat Genet 41:1345-1349

28. Lui G, Bouazza N, Denoyelle F et al (2018) Association between genetic polymorphisms and platinum-induced ototoxicity in children. Oncotarget 9:30883-30893

29. Pincinato EC, Costa EFD, Lopes-Aguiar L (2019) GSTM1, GSTT1 and GSTP1 Ile105Val polymorphisms in outcomes of head and neck squamous cell carcinoma patients treated with cisplatin chemoradiation. Sci Rep 9:9312

30. Liberman PHP, Goffi-Gomez MVS, Schultz C et al (2019) Contribution of the GSTP1 c.313A > G variant to hearing loss risk in patients exposed to platin chemotherapy during childhood. Clin Transl Oncol 21:630-635

31. Peters U, Preisler-Adams S, Hebeisen A et al (2000) Glutathione Stransferase genetic polymorphisms and individual sensitivity to the ototoxic effect of cisplatin. Anti-Cancer Drugs 11:639-643

32. Oldenburg J, Kraggerud SM, Brydøy M, Cvancarova M, Lothe RA, Fossa SD (2007) Association between long-term neuro-toxicities in testicular cancer survivors and polymorphisms in glutathione-s-transferase- $\mathrm{P} 1$ and -M1, a retrospective cross sectional study. J Transl Med 5:70

33. Rednam S, Scheurer ME, Adesina A, Lau CC, Okcu MF (2013) Glutathione S-transferase P1 single nucleotide polymorphism predicts permanent ototoxicity in children with medulloblastoma. Pediatr Blood Cancer 60:593-598

34. Biró K, Baki M, Büki B, Noszek L, Jókuti L (1997) Detection of early ototoxic effect in testicular cancer patients treated with cisplatin by transiently evoked otoacoustic emission: a pilot study. Oncology 54:387-390

35. Biró K, Noszek L, Prekopp P et al (2006) Characteristics and risk factors of cisplatin induced ototoxicity in testicular cancer patients, detected by distorsion product otoacoustic emission. Oncology 70:177-184

36. Smoorenburg GF, De Groot JC, Hamers FP, Klis SF (1999) Protection and spontaneous recovery from cisplatin-induced hearing loss. Ann N Y Acad Sci 884:192-210

37. Truong MT, Winzelberg J, Chang KW (2007) Recovery from cisplatin-induced ototoxicity: a case report and review. Int J Pediatr Otorhinolaryngol 71:1631-1638

38. Knight KR, Chen L, Freyer D et al (2017) Group-wide, prospective study of ototoxicity assessment in children receiving cisplatin chemotherapy (ACCL05C1): a report from the Children's Oncology Group. J Clin Oncol 35:440-445

39. Angeli SI, Bared A, Ouyang X, Du LL, Yan D, Zhong Liu X (2012) Audioprofiles and antioxidant enzyme genotypes in presbycusis. Laryngoscope 122:2539-2542

40. Shen H, Huo X, Liu K et al (2012) Genetic variation in GSTM1 is associated with susceptibility to noise-induced hearing loss in a Chinese population. J Occup Environ Med 54:1157-1162

41. Cohen J (2018) Hidden causes of high or low blood urea nitrogen (BUN). www.selfhacked.com/blog/causes-of-high-or-low-bloodurea-nitrogen-bun/. Accessed 20 June 2018

42. D'Apolito M, Du X, Pisanelli D et al (2015) Urea-induced ROS cause endothelial dysfunction in chronic renal failure. Atherosclerosis 239:393-400

43. Thiesen S, Yin P, Jorgensen AL et al (2017) TPMT, COMT and ACYP2 genetic variants in paediatric cancer patients with cisplatininduced ototoxicity. Pharmacogenet Genomics 27:213-222

Publisher's note Springer Nature remains neutral with regard to jurisdictional claims in published maps and institutional affiliations. 